\title{
Moving Laboratory Education to the Cloud: Support for Quality Engineering and Management Courses
}

\author{
http://dx.doi.org/10.3991/ijac.v6i3.3326 \\ K. Zgodavova, M. Horvath \\ Technical University of Košice, Košice, Slovakia
}

\begin{abstract}
The purpose of this paper is to provide a generalized knowledge of the development and testing of cloudbased creative laboratory education. The paper provides interested parties an efficient interconnection of information necessary for research, education and practical experience in the subjects of Quality Engineering and Management study program between technical universities. The paper summarizes the final findings of the KEGA 009TnUAD/2011 CRELABTE project -supported by Ministry of Education, Science, Research and Sport of the Slovak Republic.
\end{abstract}

Index Terms-laboratory education, creativity, quality engineering and management, cloud learning

\section{INTRODUCTION}

Universities are continued pressured to reduce the expense associated with laboratory education of undergraduate engineering students. Many alternatives to traditional laboratory instruction have been trialed to improve the educational benefits and to reduce the academic input [1].

Cloud computing (CC) is the promising infrastructure which can provide tremendous values to e-learning ecosystems, due to its abilities to deliver computation and storage resources as services [2]. The main advantage of cloud computing is the flexibility it offers to create, share, save and collaborate from anywhere, at any time [3]. One of cloud computing models is Software as a Service (SaaS). In this form of cloud computing, a customer runs software remotely, via the Internet, using the service provider's programs and computer infrastructure [4]. Mäkilä et al. further mention that "in the SaaS model customer buy a subscription to the software and the service provider runs and maintains the software on his own hardware. Users with current subscriptions can obtain access to the software using the Internet".

Recent progress in computing, multimedia, and communication technology provide an opportunity to build a self-growing, unit sharing virtual environment for teaching and learning [5]. There are a number of related projects cloud-based applications in e-learning, and remote laboratories separately. Marenzi, et al. [6] investigated how social software can be used in formal learning or work environments, and how to develop and integrate models and tools into an open source infrastructure for the creation, storage and exchange of learning objects, suitable knowledge resources as well as learning experiences.

Cloud learning can actually help institutions to reduce high expenses on hardware, software, IT maintenance and provides Higher Education Institutions (HEI) with a centralized, virtual data center that is accessible to faculty and admissions personnel, any time and at any location [7]. Basis of this paper is ongoing knowledge of KEGA 009TnUAD/2011 CRELABTE project, supported by Ministry of Education of Slovak Republic and are connected to the structure, targets and objectives of the laboratory and cloud computing featuring usage in Interactive Collaborative Learning. Starting point and description of the project were presented at the $14^{\text {th }}$ International Conference on Interactive Collaborative Learning [8].

\section{CRelabte Cloud Learning}

CRELABTE is a service that is applying the model of SaaS cloud computing for providing access to virtual laboratories and software for teaching purposes.

The mission of CRELABTE cloud learning is to provide interested parties with effective information and synchronization necessary for research, education and industry practice in scope of quality engineering and management study programs and related laboratory education between Slovak Universities. CRELABTE cloud consists of four virtual laboratories providing opportunities for observation, measurement and experimentation with the purpose-reasoned process situations, objects and phenomenon in studied field (Fig.1): (a) Virtual laboratory of Engineering Metrology (EM) - providing options for remote measurements of geometrical and electrical values; (b) Virtual laboratory of Engineering Statistics (ES) - providing possibilities to exploit tools and methods of Statistical Process Control (SPC) and Statistical Quality Control (SQC); (c) Innovation Laboratory (IL) - enhance creative thinking and innovative action of students; (d) Laboratory of Management Systems (MS). Work methods are designed according to the pre-draft proposal formulated solutions, recognized rules of good laboratory practice and competence measurement procedures specified in the instructions for work in Cloud Learning environment. 


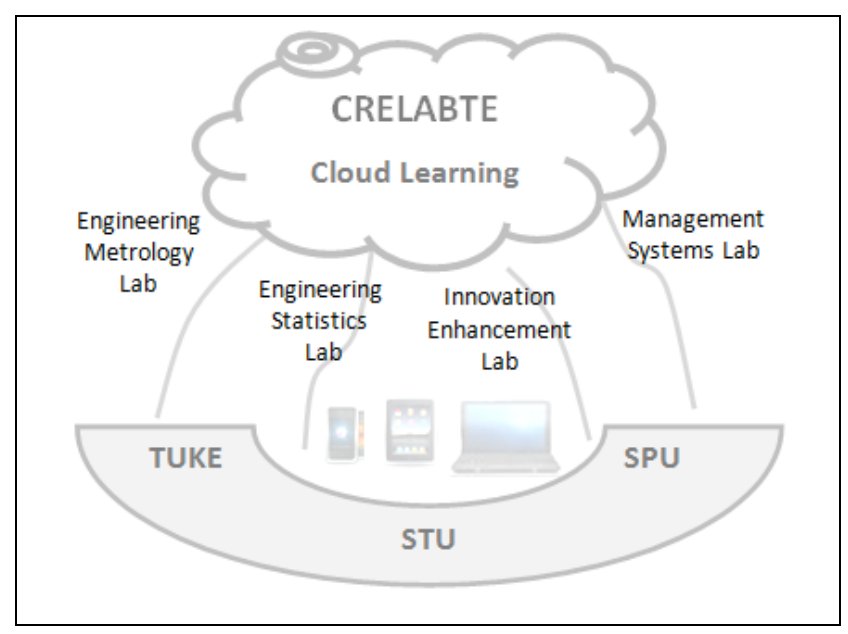

Figure 1. CRELABTE cloud virtual laboratories

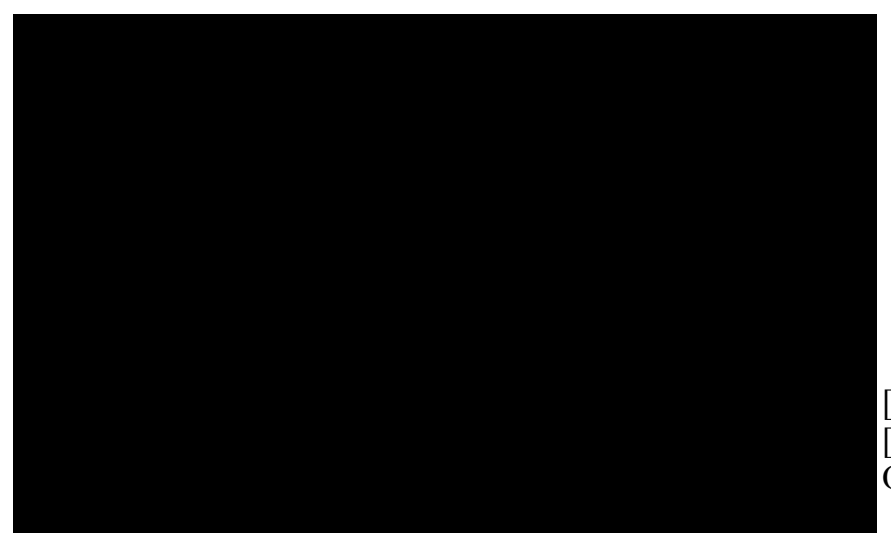

Figure 2. Road map of the CELABTE project

The leading objectives of Engineering and Management study program at the Technical University of Kosice, Department of Integrated Management are achieved by initial understanding of laboratory teaching [3] as a place of providing the factual and general knowledge about real and virtual entities. Entities measurement affecting the quality, security, environment, performance, economic efficiency and social responsibility of organizations are taken in CRELABTE cloud laboratories according to teaching targets in the courses. The essence of such laboratory measurements (in the broad sense according to [3]) is gathering knowledge by comparing entities with their patterns and description of measurement sub-processes in classification: purpose reasoning, design, realization and measurement results providing to achieve of organizations success. Learning is designed and is taken in Moodle e-Learning environment. Virtual laboratories are providing a wide range of services.

\section{EXAMPLES OF USING VIRTUAL LABORATORIES CRELABTE}

An example of Engineering Metrology virtual laboratory measurements is on Fig. 3. Faculty is not equipped with its own laboratories for measuring the geometrical and electrical values that is why the measurement records from metrology laboratory of Mechanical Engineering Faculty are used. Another assignment, for example when teaching indirect measurement, is conduct- ed by using special software installed in CRELABTE server. During SPC and SQC exercises, students have an opportunity to simulate the behavior of managers performing management tasks and controllers in production areas. For example, they visually evaluate the quality of products and using intuitively controlled touch screens and bar codes scanner they send the data to the database of Engineering Statistics virtual laboratory. By using KONIS software "in press" [9], which is installed in CRELABTE, they solve other given tasks.

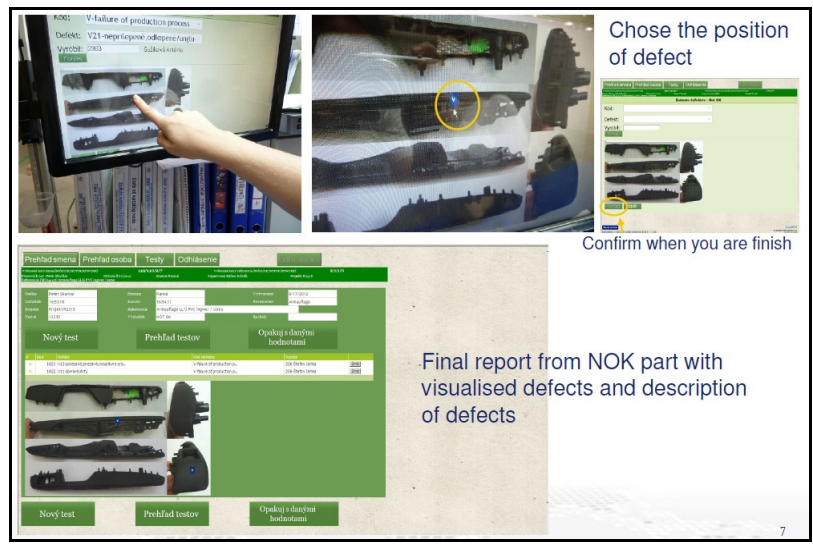

Figure 3. Laboratory experiments based on indirect measurements

Other statistical exercises [10], [11] as e.g. Six Sigma [12], [13] can be solved by using software Quantum XL [14] or balancing Key Performance Indicators [15] by QPR Balanced Scorecard [16].

In the Management Systems virtual laboratory are conducted exercises related to management subjects, students design management systems, they virtually audit and improve them by using Simulation Role Play (SIMPRO-MS) [17].

For process modeling and simulation is used software QPR 8.1 Process Guide [18] installed on CRELABTE server.

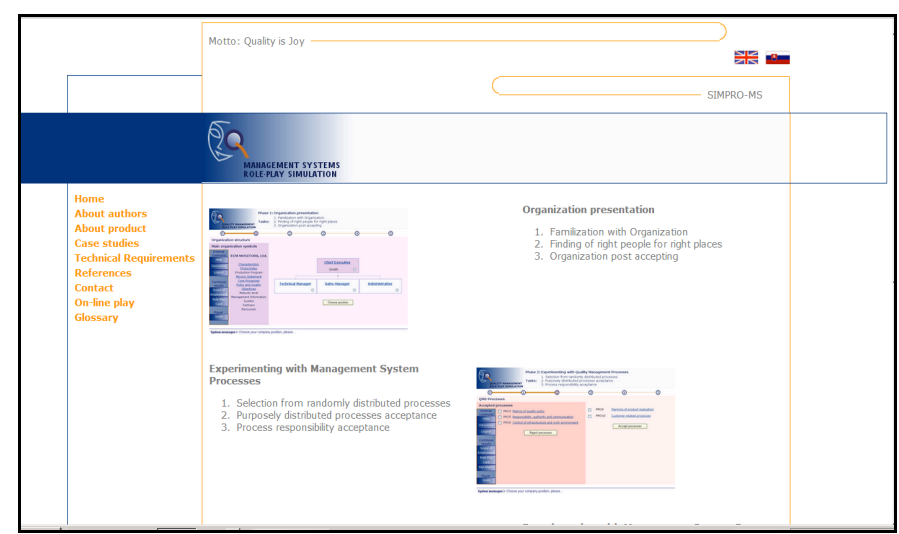

Figure 4. Role Pay Simulation using Management Systems laboratory

An example of Innovation Enhancement virtual laboratory researching result is on Fig. 4 . Under the teacher's supervision, students gain data about what product expcectation customer have and using the software Kansei Engineering [19] they design products applying the QFD method, meanwhile software is again installed in CRELABTE 


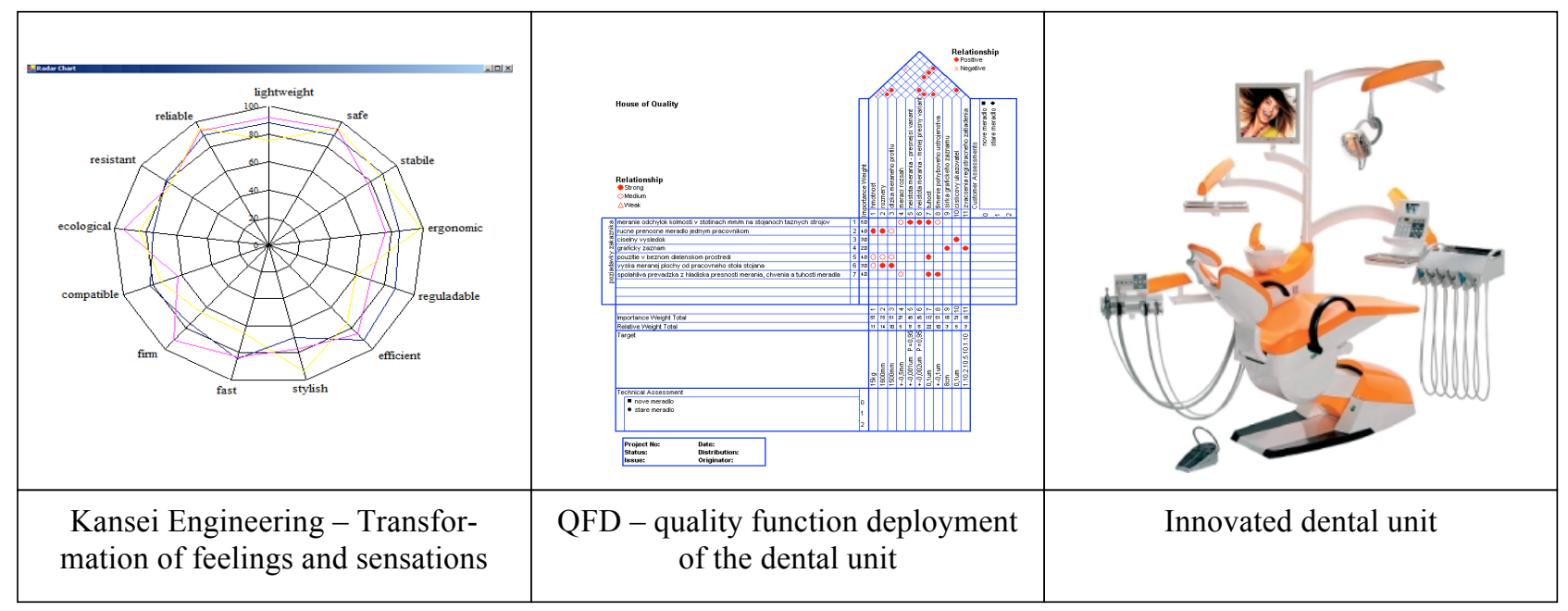

Figure 5. Dental unit innovation using CRELABTE virtual laboratories [20]

Teachers from different places can moderate their lessons using any virtual laboratory and create new teaching tasks by using of different media. The findings from new measurements, e.g. final thesis, are stored in such database.

Necessary entries are stored in relation databases and disc arrays in the data center. That improves the security of the data and facilitates re-usage of these data. An example of teaching subject: Tools and methods of quality management, topic: Quality Function Deployment (QFD) is model solutions of customers' voice transformed to properties and functions of product stored in the database.

SaaS cloud based model of CRELABTE provides access to the customized virtual laboratory. Teacher can specify the number of students (CRELABTE users) and select virtual laboratory or its parts that will be accessible for students.

The device that supports the Remote Desktop Software (RDP) technology is required for connection. Such device is for example personal computer, notebook or most smartphones and tablets. The SaaS model of CRELABTE can be useful, not just for formal education, but or companies that can train their staff using the customized laboratory education.

\section{CONCLUSION}

The overall findings showed that cloud learning as a solution for education proved to be effective from education and user perspective because (a) It provides the teacher with higher flexibility and reduces costs to prepare an experiment, as well as bring higher efficiency and accuracy in conducting an experiment; (b) provides for students higher value by delivering accurate and correct result and measurement process.

Over two years, of testing experiments showed that students and teachers are extremely satisfied, learning objectives were achieved, and the results of testing of knowledge showed improvement over the previous year.
Students and teachers creative thinking is developed by changing of awareness of features, functions, tolerances and other variables measured entity (whether in the narrow or broad sense) and their resulting effects on the function of the product or system as a whole. Project results are intended to faculties of Technical University of Kosice (TUKE), Slovak Technical University of Bratislava (STU) and Slovak Agricultural University in Nitra (SPU), which provide studies in the field of quality engineering and management. Project results can also properly serve to the other similarly oriented technical schools in Europe. In next academic year testing of CRELABTE cloud will start at University of Hradec Kralove, Czech Republic. Further plans for CRELABTE cloud solution is the creation of English versions of laboratory instructions and expanding of remote experiments and measurements.

\section{ACKNOWLEDGMENT}

Research presented in this paper is supported by the project of the Slovak Republic Ministry of Education KEGA 009-4/2011: Creative Laboratory Education at Technical Faculties "CRELABTE”.

\section{REFERENCES}

[1] Mackechnie, J. and Buchanan, A. "Creative Laboratory Model for Large Undergraduate Engineering Classes." J. Prof. Issues Eng. Educ. Pract., 138(1), pp. 55-61, 2012. http://dx.doi.org/10.1061// ASCE)EI.1943-5541.0000081

[2] Dong, B., Zheng, Q., Yang, J., Li, H., Qiao, M., "An e-Learning Ecosystem Based on Cloud Computing Infrastructure" in $9^{\text {th }}$ IEEE International Conference on Advanced Learning Technologies, 2009, pp. 125-127.

[3] Bogiannidis, N. „Welcome to cloud education,“ Cloud Education, [Online]. Available: http://www.cloudeducation.com.au/. [Cit. 15 4. 2013].

[4] Mäkilä1 T., Järvi1 A., Rönkkö M., Nissilä J., "How to Define Software-as-a-Service - An Empirical Study of Finnish SaaS Providers", In Software Business First International Conference, ICSOB 2010, , 21-23, June 2010, Jyväskylä, Finland pp 115-124, DOI 10.1007/978-3-642-13633-7_10.

[5] Al-Zoube M. E-Learning on the Cloud. International Arab Journal of e-Technology, Vol. 1, No. 2, June, 2009.

[6] Marenzi I., Demidova E., and Nejdl W. "LearnWeb 2.0. Integrating Social Software for Lifelong Learning," In 


\section{SHORT PAPER}

MOVInG LABORATORY EDUCATION TO THE Cloud: SuPPORT FOR QUALITY ENGINEERING AND MANAGEMENT COURSES

Proceedings of the ED-Media 2008. World Conference on Educational Multimedia, Hypermedia \& Telecommunications, 2008.

[7] Lepi, K. „The Future of Higher Education and Cloud Computing" Edudemic, 2. 2. 2013. [Online]. Available: http://edudemic.com/2013/02/higher-education-and-cloudcomputing/. [Cit. 4. 10. 2013].

[8] Zgodavova, K., Zolotova, I., Roznik, J., "Creative Laboratory Engineering Education at Technical Faculties (The Pilot Project)" In $14^{\text {th }}$ International Conference on Interactive Collaborative Learning (ICL2011) 11 $1^{\text {th }}$ International Conference Virtual University (vu'11) 21-23 September 2011, Piešt'any, Slovakia pp. 632.

[9] Lengyel, L. (2013): "Management system for acquisition analysis and evaluation of data from process with manual entry" Quality Innovation Prosperity, Vol. No 2, 2013, in press.

[10] Hudec, O.; Sisakova, J.; Tartalova, A.; Zelinsky, T. Statisticke metody v ekonomickych vedach. Elfa, Kosice, 2007.

[11] Bober, P. "Simulátor regulačných diagramov pre výučbu štatistického riadenia procesov (Control Chart Simulator for teaching Statistical Process Control)". Q-magazín. No. 9, pp. 1-7, (2013), ISSN 1213-0451, http://katedry.fmmi.vsb.cz/639/st15cz.pdf.

[12] Tošenovský , F. "A Mathematical Model for Process Cycle Time - Theory and Case Study”. Kvalita Inovácia Prosperita / Quality Innovation Prosperity. Vol 14. No. 1, pp. 64-71, 2010.

[13] Tošenovský, J, Tošenovský, F.: "Possibilities of Production Process Financial Assessment'In Proceedings from the Financial Management of Firms and Financial Institutions Conference, Ostrava 9.- 10.9.2013, 2013.
[14] Quantum XL, ver 3.51.0530, Sigma Zone.

[15] Šoltés, V., Gavurová, B. "Application of the cross impact matrix method in problematic phases of the balanced scorecard system in private and public sector" Journal of Applied Economic Sciences, Volume 8, Issue 1, 2013, pp. 99-119, 2013.

[16] QPR Balanced Scorecard, ver. 8.1, QPR Software Plc, Helsinki, Finland.

[17] Zgodavova, K., Bober, B. "An Innovative Approach to the Integrated Management System Development: SIMPRO-IMS Web Based Environment". Quality Innovation Prosperity. Vol. 16, No. 2, pp. 59-71, 2012. http://dx.doi.org/10.12776/ qip.v16i2.69

[18] QPR Process Guide, ver. 8.1, QPR Software Plc, Helsinki, Finland

[19] KESoft Kansei Engineering Expert Software, ver 2.1, Peter Hallberg, Linköping University, Linköping, Sweden.

[20] Ešše, M., "Quality function deployment of mechatronic production", Phd disertation, Dept. of Electrical Engineering and Mechatronics, Technical University of Košice, Slovakia, 2011.

\section{AUTHORS}

K. Zgodavova and M. Horvath are with the Department of Integrated Management, Technical University of Košice, Slovakia.

Submitted 09 October 2013. Published as re-submitted by the authors 15 November 2013. 